\title{
NICOTINE SELF-ADMINISTRATION IN ANIMALS: A REEVALUATION
}

\author{
REUVEN DAR $^{\mathrm{a}, *}$ and HANAN FRENK ${ }^{\mathrm{b}}$ \\ ${ }^{a}$ Department of Psychology, Tel Aviv University, Tel Aviv 69978, Israel; \\ ${ }^{b}$ The Academic College of Tel Aviv-Yafo and Tel Aviv University
}

\begin{abstract}
Nicotine self-administration in animals is often viewed as compelling evidence that nicotine is reinforcing to animals and as corroborating the widely accepted thesis that nicotine is a major cause of smoking. This review examines the studies of nicotine self-administration in animals in the past two decades, focusing on threats to the internal and external validity of these studies and on the extent to which they support the thesis that nicotine is reinforcing in animals. The review shows that nicotine self-administration studies are fraught with severe methodological problems. These include omission of essential controls for general activation and other systemic effects of nicotine, insufficient consideration of secondary reinforcement processes, using food-deprived or confined animals and exclusion of subjects that do not conform to the investigators' preferred behavior. As a result of these systematic flaws, the role of nicotine as a reinforcer in this paradigm has not been established.
\end{abstract}

Keywords: Self-administration; Nicotine; Reinforcer; Animal; Intravenous; Oral

In 1988, The US Surgeon General (US Department of Health and Human Services, 1988) officially declared that nicotine was an addictive drug, stating that "Nicotine is the drug in tobacco that causes addiction" and that "The pharmacologic and behavioral processes that determine tobacco addiction are similar to those that determine addiction to drugs such as heroin and cocaine (p. 9)." This view, which was "enshrined" (Stolerman and Jarvis, 1995) both within the scientific community and in the public opinion, was recently reiterated by the British Royal College of Physicians (Tobacco Advisory Group of The Royal College of Physicians, 2000).

\footnotetext{
*Corresponding author. Fax: 972-3-6409547. E-mail: ruvidar@freud.tau.ac.il
} 
The wide acceptance of the nicotine addiction thesis has important implications. Practically all present plans regarding the fight against smoking and the regulation of tobacco products are based on the assumption that cigarettes are basically nicotine delivery devices (e.g., Henningfield and Keenan, 1993). For example, according to the recent report of the British Royal College of Physicians (Tobacco Advisory Group of The Royal College of Physicians, 2000), "nicotine dependence is heavily entrenched in society. It is obviously desirable to reduce both nicotine dependence and the terrible harm caused by nicotine delivery through tobacco smoke, but it may be necessary to accept, albeit reluctantly, the intractability of widespread nicotine dependence in the short to medium term. In this case, product developments that enable nicotine users to take nicotine with less harm to their health should be encouraged" (p. 187). Obviously, this type of recommendation makes little sense if nicotine is not the reason that people smoke cigarettes.

Moreover, several studies demonstrated that the more smokers believe that they are addicted, the more difficult they perceive quitting to be (Katz and Singh, 1986; Martin, 1990; Jenks, 1994) and the less confident they are about their own chances of quitting (Eiser and van der Plight, 1986; Eiser et al., 1985). The belief that smoking is an addiction seems to be a self-fulfilling prophecy, as it is associated with shorter duration of cessation attempts and higher relapse rates (Owen and Brown, 1991). Smokers' belief that they are chemically addicted may lead to an external attribution of control over smoking and undermine their sense of self-efficacy (Bandura, et al., 1980).

We have extensively reviewed and critiqued the empirical basis for the nicotine addiction hypothesis elsewhere (Frenk and Dar, 2000). More recently, Atrens (2001) has also questioned the conceptual and the empirical basis for the accepted claim that nicotine is an addictive substance. The present article expands this critique by focusing on one of the major paradigms on which the nicotine addiction hypothesis is based, namely the self-administration paradigm.

The primary criterion used by Surgeon General to determine that nicotine was addictive, and indeed that any drug was addictive, was that "the psychoactive chemical must be capable of functioning as a reinforcer that can directly strengthen behavior leading to further drug ingestion (p. 8) (US Department of Health and Human 
Services, 1988)." Consequently, much of the experimental work designed to establish that nicotine was addictive was directed at establishing its primary reinforcing properties.

The principal paradigm used to assess the presumed reinforcing properties of nicotine has been its voluntary self-administration in animals. It is commonly assumed that self-administration of nicotine has been established and that nicotine therefore meets this necessary criterion for being an addictive drug (e.g., US Department of Health and Human Services, 1988; Stolerman and Jarvis, 1995; Tobacco Advisory Group of The Royal College of Physicians, 2000). The present article reviews and critiques the nicotine self-administration literature and reexamines whether this conclusion is warranted by the data.

\section{PROBLEMS IN ESTABLISHING THE REINFORCING PROPERTIES OF NICOTINE}

In order to establish that a particular drug is reinforcing, any selfadministration study must control for various alternative explanations that could account for its results. Additionally, the specific properties of nicotine present unique problems that must be addressed by animal studies aiming to investigate its reinforcing properties. Although some of these problem are shared by known reinforcing drugs, in particular the psycho-stimulants amphetamine and cocaine, they are much more crucial in the case of nicotine. In contrast to the case of amphetamine and cocaine, whose reinforcing properties are directly observable and reportable in human users, the claim that nicotine has reinforcing properties depends critically on the results of animal self-administration studies. Needless to say, the fact that some other drugs are also poorly self-administered, or that "as late as, 1971, even morphine and cocaine were, by some criteria, weak reinforcers (Stolerman and Jarvis, 1995, p. 5)" cannot be taken as positive evidence for the presumed reinforcing properties of nicotine in animals.

We begin with a review of the general as well as the specific problems associated with studying nicotine self-administration. We then proceed to critique the body of nicotine self-administration studies, and specifically the extent to which they have addressed and solved these problems. 


\section{Nicotine Produces General Activation and Stimulates Ongoing Behavior}

Nicotine, at low doses, increases overall activity in rats. At higher doses, nicotine initially depresses and then activates ongoing behavior (e.g., Kuschinsky and Hotovy, 1943; Rosecrans, 1969; Morrison and Stephenson, 1972; Stolerman et al., 1973; Battig et al., 1976; Schlatter and Battig, 1979; Schaefer and Michael, 1986, 1992; Jerome and Sandberg, 1987; Clarke et al., 1988; Hakan, 1988; Fung, 1990; Museo and Wise, 1990; Reavill and Stolerman, 1990; Corrigall and Coen, 1991, 1994; O'Neill et al., 1991; Helton et al., 1993; Brioni et al., 1994; Shoaib et al., 1994; Reid et al., 1998; Nadal and Samson, 1999). Tolerance of the depressant effect occurs and, subsequently, the stimulant action of nicotine becomes more pronounced with repeated administration (e.g., Clarke and Kumar, 1983a, b; Weltzl et al., 1988). In all of the above experiments, nicotine increased spontaneous locomotion. The nicotine antagonist mecamylamine blocks both the depressant and the stimulant effects, indicating that both are produced by nicotinic receptors (Clarke and Kumar, 1983a, b).

Increased activation can affect various responses made by animals. Clarke and Kumar (1983c) tested the effects of nicotine in rats trained to shuttle for rewarding electrical brain stimulation. They noted that with repeated daily nicotine injections, a marked, dosedependent, stimulant effect emerged. Significantly, this effect continued even when brain stimulation was turned off. These results were replicated by the authors themselves and by another team (Clarke and Kumar, 1984; Schaefer and Michael, 1986). Others have shown that nicotine activates other operant behaviors such as lever-pressing for food (Morrison, 1967; Pradhan, 1970; White and Ganguzza, 1985; Goldberg et al., 1989; Lau et al., 1994) or for water (Glick et al., 1996).

In summary, nicotine in low doses or in repeated administration stimulates any ongoing behavior, including lever pressing. Therefore, as Wise and Bozarth (1987) pointed out, when the animal presses a lever to self-administer nicotine, it may enter a positive feedback loop in which nicotine activates further pressing for nicotine not because of its reinforcing properties, but because of its activating ones. 
This possibility gains credence from the finding that rats pressing a lever for intravenous nicotine also pressed more on a second lever, which had no reinforcing consequences (Cox et al., 1984). This is a finding that highlights the nonspecific activating effect of nicotine in self-administration studies. Similarly, the observation that selective dopamine antagonists blocked both nicotine-induced locomotion and nicotine self-administration (Corrigall and Coen, 1991a) suggests that these antagonists reduce the nonspecific stimulant effects of nicotine.

Thus, the observation that nicotine stimulates any ongoing behavior, a property that may play a major role in nicotine self-administration, is well established. This effect must be carefully controlled if selfadministration is to be interpreted as indicating that nicotine is reinforcing. As the review below will show, however, the vast majority of nicotine self-administration studies did not make any attempt to control for this effect.

\section{Food Deprivation Induces Nonspecific Activation}

In many studies of nicotine self-administration, the rats are food deprived before the start of the conditioning procedure (e.g., Donny et al., 1998; Corrigall and Coen, 1989). The reason for this is that in contrast to the case of powerfully reinforcing drugs such as morphine, heroin, and cocaine (Bozarth and Wise, 1985; Nishida and Chiba, 1991; Martin et al., 1995; Wise et al., 1995; Vela et al., 1998), rats that are not hungry are reluctant to self-administer nicotine (e.g., Watkins et al., 1999). But whereas food deprivation is often essential to get the rats to use nicotine, it introduces another confounding factor in these studies: Hunger activates behavior in rats, a phenomenon just as well documented as the stimulating effect of nicotine. Food-restriction causes a remarkable increase in the use of activitywheels and may lead to the cessation of the estrous cycle in females, loss of body weight, and even self-starvation (e.g., Routtenberg and Kuznesof, 1967; Routtenberg, 1968; Spatz and Jones, 1971; Woods and Routtenberg, 1971; Santos and Routtenberg, 1972; Kanarek and Collier, 1983; Spigelman et al., 1991; Watanabe et al., 1992; Lett and Grant, 1996; Lett et al., 1997), a phenomenon that has been proposed as an animal model of anorexia nervosa (Aravich et al., 1985; 
Pirke et al., 1993; Davis et al., 1994; Davis, 1997; Davis and Claridge, 1998). Such general activation may well increase the rate of lever pressing in self-administration studies, an effect that is liable to be falsely attributed to the reinforcing properties of nicotine.

\section{Confounds with Previous Conditioning}

In many nicotine self-administration studies, animals are pretrained to self-administer known reinforcing agents such as food, water, or other drugs such as cocaine, and are subsequently switched to nicotine (e.g., Risner and Goldberg, 1983; Corrigall and Coen, 1989; Sannerud et al., 1994; Donny et al., 1998; Stolerman et al., 1999). In none of the selfadministration studies reviewed here, however, were the animals subjected to an adequate extinction procedure. Consequently, for at least the first 5-10 nicotine self-administration sessions, the results are confounded: They reflect not only nicotine-reinforced pressing, but also the residual effects of the original reinforcer. In subsequent sessions, the animals are presumed to have "forgotten" the original reinforcer, so that continued lever pressing now reflects the reinforcing power of nicotine. This presumption is problematic, and as we shall see later, it is also not supported by the data.

In summary, the discussion above shows that careful controls must be employed so that self-administration of nicotine can be attributed with confidence to the reinforcing properties of nicotine. We now turn to a review of the research literature on nicotine self-administration in animals. The main aim of the review is to examine to what extent these requisite controls were actually employed in this paradigm.

\section{ORAL SELF-ADMINISTRATION OF NICOTINE}

Only a small minority of studies reported that certain animals, such as the tree shrew (Opitz and Weischer, 1988), prefer drinking nicotine solution to water. The general finding is that rats, mice, and squirrel monkeys normally do not prefer nicotine solutions to water (Hutchinson and Emley, 1988; Flynn et al., 1989; Robinson et al., 1996). Nevertheless, two recent reports claim to have demonstrated a preference for oral nicotine over control solutions in rats. We will 
discuss them in some detail, because they demonstrate some of the pitfalls of this line of research.

The first report, by Smith and Roberts (1995), describes four experiments. The first study aimed to investigate "whether rats could be induced to consume nicotine orally (p. 342)" by adding sucrose to nicotine solution. The study showed that adding sucrose indeed induced the rats to consume the nicotine solution. However, the intake of sucrose + nicotine never exceeded that of sucrose alone, and in two concentration levels was significantly lower. Therefore, if there was any trend in the findings of this study, it was that rats preferred the sucrose solution that did not contain nicotine.

The second experiment in this study was designed to see whether rats would perform an operant response for nicotine reward. The rats were housed in operant chambers containing ad libitum food and water, as well as a lever and a cup. For one group of rats, pressing the lever would squirt a small amount of a sucrose solution into the cup. For the second group of animals, a lever press would produce the same amount of sucrose solution mixed with nicotine. The results showed that the rats that were reinforced with sucrose + nicotine tended to press the lever somewhat more than the rats that received only sucrose, but this difference did not even approach statistical significance ( $p$ was 0.27). Furthermore, even this nonsignificant effect cannot be attributed to the reinforcing effects of nicotine. For an unspecified reason, the rats that were to be trained to work for sucrose + nicotine were maintained on the same sweet nicotine solution two weeks prior to the training, and then continued to have free access to this solution between the operant training trials. As a result, these rats must have been highly aroused, which fully accounts for any tendency to press the lever more frequently. Moreover, when the sucrose concentration was gradually reduced, the rats receiving sweet water + nicotine reduced their response at exactly the same rate as the rats who were receiving just the sucrose solution. This finding strongly suggests that the rats in this study pressed for sucrose, not for nicotine.

In the third experiment in this study (Smith and Roberts, 1995), the fixed ratio was gradually increased from FR5 to FR20. As the ratio increased, and specifically between FR7 and FR16, sucrose + nicotine reinforced rats pressed more frequently than rats reinforced with sucrose alone. The authors concluded, on the basis of these 
findings, that "sucrose + nicotine solutions are more reinforcing than sucrose solutions alone (p. 341)." In making this unequivocal statement, which appears in the abstract of the article, Smith and Roberts apparently did not consider the alternative explanations discussed above. Specifically, the increased response rate of the nicotine + sucrose rats could be due to nicotine's augmentation of general activation and, especially in the higher reinforcement schedules, also to its enhancement of memory consolidation.

Interestingly, Smith and Roberts seem to have been aware of the severe limitations of their study. In the discussion section of their article, they added this qualification: "It must be emphasized that the enhanced responding for the SUC + NIC solution was demonstrated in animals that had been ingesting nicotine for several months. Whether animals with less experience with nicotine would respond to higher FR values is presently unknown (p. 345)." Moreover, in contrast to their statement in the abstract, their conclusion in the body of the article is carefully stated: "When a response criterion is enforced, the response maintaining effects of sweetened nicotine solutions are greater than those of comparable sucrose-only solutions (p. 345)." The difference between "response maintaining" and "reinforcing" is telling. Indeed, the findings of a subsequent study of oral nicotine preference corroborate the hypothesis that increased response rate in these paradigms is attributable to the general activating effects of nicotine.

In this subsequent study, Glick et al. (1996) used a different procedure than that of Smith and Roberts. They placed rats in operant chambers equipped with two levers and two cups. The rats were deprived of water for $23 \mathrm{~h}$ per day and then trained to press for plain water for $1 \mathrm{~h}$. Both levers were "active", so that pressing on either lever was rewarded with a droplet of water in the cup above that lever. After the rats had acquired stable levels of lever pressing, nicotine solutions were introduced. A press on lever $A$ squirted plain water, whereas a press on lever $B$ produced a nicotine solution. The levers were alternated every session. The concentration of nicotine was doubled once a week.

This two lever choice situation demonstrated unequivocally that nicotine produces general activation, which, in this setting, was expressed in frequency of lever pressing. The most significant finding in this study was that as nicotine levels were increased, the rate of 
lever pressing on both levers increased in a parallel fashion (from about 100 per hour at a nicotine concentration of $4 \mu \mathrm{g} / \mathrm{mL}$ to 160 per hour at a nicotine concentration of $32 \mu \mathrm{g} / \mathrm{mL}$ ). This finding supports the hypothesis that what Smith and Roberts (1995) reported as a reinforcing effect of nicotine was most likely a nonspecific stimulant effect.

Regarding preference for nicotine over plain water, the investigators reported that 16 of the 20 rats "reliably preferred bar-pressing to receive nicotine, at $4-32 \mu \mathrm{g} / \mathrm{mL}$, than to receive water" (Glick et al., 1996, p.427). However, no significance tests of these difference are reported, and the meaning of "reliably" remains unclear. The authors do report that four rats $(20 \%)$ never preferred nicotine. Whether or not the other 16 rats preferred nicotine at every concentration level in this range, and in which sessions, cannot be discerned from the aggregated presentation of the data. Moreover, a recent report from the same group, using identical methodology, indicates that the finding that $80 \%$ of the rats preferred nicotine in the Glick et al. (1996) study is in fact quite unreliable. For their second study (Glick et al., 1998), the researchers selected only rats that demonstrated a preference for nicotine in this paradigm. In parentheses, they explain that "not all rats have nicotine preference" and that, specifically, "approximately $50 \%$ of the rats screened for this study had nicotine preferences" (Glick et al., 1998, p.275). Glick and his colleagues do not attempt to account for the contradiction between these figures and those reported in the original study. Clearly, if only $50 \%$ of the rats prefer nicotine in this paradigm, it hardly warrants the title of "an oral self administration model of nicotine preference in rats" (Glick et al., 1996, p.426).

\section{INTRAVENOUS SELF-ADMINISTRATION}

The problems caused by nicotine's bad taste can be circumvented by training animals to self-administer nicotine intravenously. This procedure has been used to establish the reinforcing properties of other drugs, including opiates, amphetamine, and cocaine. With these drugs, however, the procedure generates much stronger evidence of reinforcement than it does with nicotine. Specifically, 
heroine and morphine (Bozarth and Wise, 1985; Nishida and Chiba, 1991; Martin et al., 1995; Wise et al., 1995; Vela et al., 1998) as well as cocaine (Wilson et al., 1971; Bozarth and Wise, 1985) not only maintain lever pressing for self-administration, but are also sufficiently reinforcing to initiate such behavior. In contrast, under normal conditions, animals do not initiate nicotine self-administration, either orally or intravenously. Only a few reports claim otherwise, and these are all problematic. In one report (Cox et al., 1984), for example, rats received multiple nicotine injections prior to intravenous nicotine self-administration, and nicotine increased response rats for both the active and the inactive lever; therefore, as discussed earlier, this result is attributable to general behavior activation. A more recent study (Valentine et al., 1997) also failed to employ adequate control for the activating effects of nicotine, and even so, the majority of its results were not statistically significant.

In other experiments reporting marginal preference for nicotine self-administration (e.g., Shoaib et al., 1997; Shoaib and Stolerman, 1999; Shoaib et al., 1999), animals received a "priming" injection of nicotine prior to each session. Such "priming" can obviously affect performance in later trails, a possibility that can be easily examined, for example, by including a control group that would receive the priming injection but would later self-administer only saline. No such group was included, however. In another recent study, which purportedly demonstrated that nicotine can initiate self-administration (Lynch and Carroll, 1999), animals were foodrestricted, some were nicotine primed, and no controls for general activation were used.

The fact that, unlike known addictive drugs, nicotine is not unconditionally self-administered by animals argues strongly against it being a potent reinforcer. But even the claim that nicotine maintains self-administration is very weakly substantiated. Most studies that have made this claim contained fundamental methodological flaws, particularly a surprising lack of controls for the nonreinforcing effects of nicotine discussed above. Our review indicates that with the exception of a handful of studies, to be discussed in detail later, nicotine self-administration studies did not attempt to rule out viable alternative explanations for their results. 


\section{Early studies (until 1989)}

Even when animals were first trained to press a lever for another reinforcer such as food and then were switched to nicotine injections, early studies often failed to demonstrate nicotine self-administration (Yanagita, 1977; Griffiths et al., 1979; Ator and Griffiths, 1983). When self-administration occurred (Lang et al., 1977; Yanagita, 1977; Hanson et al., 1979; Smith and Lang, 1980; Dougherty et al., 1981; Ator and Griffiths, 1983; Slifer and Balster, 1985), it was often marginal, not dose-related, or demonstrated only in food-deprived animals (a limitation we will discuss below). Several studies (e.g., Goldberg et al., 1981; Goldberg and Spealman, 1982; Spealman and Goldberg, 1982; Ator and Griffiths, 1983; Silfer and Balster, 1985; De La Garza and Johanson, 1987) used very few subjects and presented almost no statistics. Often the animals had participated in earlier studies where they had been trained to self-administer food or known reinforcing drugs such as cocaine. Some of the studies reporting success and quoted by the Surgeon General are available only in abstract form and hence do not permit scrutiny of the methods (e.g., Goldberg and Henningfield, 1983; Prada and Goldberg, 1985).

A 1988 review (Goldberg and Henningfield, 1988) concluded: "The series of studies reviewed show that nicotine by itself can serve as an effective reinforcer for humans and experimental animals, but it does so under a more limited range of conditions than do other reinforcers such as IV cocaine injection or food presentation" (p. 233). The "limited range of conditions" clause indicates that the reliability of animal models for intravenous self-administration of nicotine, at least at the time, was inadequate. This state of affairs is reflected in another summary of the early self-administration studies (Corrigall and Coen, 1989): "While these studies have suggested that nicotine might serve as a reinforcer in rodents, they have not provided convincing evidence" (p. 473).

Indeed, what the Surgeon General and most other investigators during the 1980s cited as evidence for the reinforcing properties of nicotine were not rodent studies, but primarily primate studies. The most influential of them was a 1981 article in Science, authored by Goldberg, Spealman and Goldberg. According to the Surgeon General's report, "Goldberg, Spealman, and Goldberg showed 
conclusively that nicotine itself could function as an efficacious positive reinforcer for animals, although the range of conditions under which it was effective was somewhat more limited than for drugs such as cocaine and amphetamine" (US Department of Health and Human Services, 1988, p. 181). Because of its influence, and especially its central place in the Surgeon General's report, this study merits detailed analysis.

The total sample in this "conclusive" study (Goldberg et al., 1981) consisted of four squirrel monkeys. The animals sat in chairs in a sound-attenuated chamber and could operate a single response lever. Pressing the lever produced a brief visual stimulus that was occasionally associated with an intravenous injection of nicotine. This secondorder reinforcement schedule produced a gradually increased rate of responding. Furthermore, substituting nicotine with saline injections or blocking nicotine receptors with mecamylamine resulted in a marked reduction in the rate of lever pressing.

While these results appear convincing at first glance (disregarding sample size), the authors did not consider two probable alternative explanations for their findings. First, as discussed earlier, nicotine induces general activation in animals. As lever pressing was the only available activity for the monkeys, nicotine would be expected to increase lever pressing. When saline was substituted for the nicotine, the activation level, and consequently the rate of lever pressing, would be expected to drop. Furthermore, as mecamylamine blocks the stimulant effects of nicotine (Clarke and Kumar, 1983a,b), it would be expected to block the increase in lever pressing induced by the general activating property of nicotine.

Second, of the four monkeys, only one was naive; the other three had been trained to press the lever for cocaine. No rationale is given for the cocaine pretraining - presumably, the authors could not otherwise get the animals to press for nicotine reward. The cocaine-trained monkeys were submitted to a saline extinction schedule. Such extinction, however, is limited, and in this case it clearly did not cause the monkeys to forget having received cocaine for lever pressing. This is evident from the fact that "in the cocaine-trained monkeys, responding was established under a second-order schedule of intravenous nicotine without preliminary training" (p. 573). Cocaine is a sufficiently powerful reinforcer to facilitate second-order conditioning as well as 
to transfer secondary reinforcing properties, by classical conditioning, to the lever the animals had been pressing. As intravenous nicotine injection is a salient cue in animals (Schechter and Rosecrans, 1972; Chance et al., 1977; Shoaib and Stolerman, 1996), it could become associated with the secondary reinforcing properties of the lever that was previously conditioned to the reinforcing effects of cocaine and, therefore, enhance responding as a secondary reinforcer.

In addition to these two crucial alternative mechanisms, there is another factor that may have influenced the results of Goldberg, Spealman, and Goldberg's study. Research conducted more than two decades ago has established that rats in a stimulus-free environment are willing to work for the light stimulus itself (e.g., Williams and Lowe, 1972; Myslobodsky, 1976; Harrington, 1979). While there is no direct evidence that monkeys will acquire level pressing with a light reward, it is a possibility that should be considered in interpreting the results of this study, especially in light of the poor reliability of the nicotine self-administration paradigm.

In addition to the researchers' failure to consider and control for alternative explanations, the design of Goldberg, Spealman, and Goldberg's study was seriously flawed. There were five manipulations in all (nicotine + mecamylamine, nicotine + no light, saline, saline + no light, and resumption of nicotine), but the design was not fully crossed: Saline was substituted for nicotine only in the three cocaine-trained monkeys; mecamylamine was administered only to two of the four monkeys, and the same was the case for omitting the light stimulus. Only one monkey received all five manipulations, and the lone nicotine-trained monkey received only two manipulations. In addition, the results did not include any statistical analysis of the data, or even tables of results, so readers are left to judge the results by eyeballing the figures. In the same vein, there were no standard definitions for a "reduction" or an "increase" in the rate of pressing. To illustrate, one monkey (S-156) increased its pressing rate by 0.7 responses per second during the four baseline sessions. When the light stimulus was omitted, another monkey (S-464) is said to have reduced its pressing rate, but this supposed reduction is only by 0.4 responses per second. Thus, in one case, a difference of 0.4 responses per second is considered a meaningful reduction, while in another case an increase of 0.7 responses per second is ignored as baseline variability. 
The order and length of the manipulations in Goldberg, Spealman and Goldberg's (1981) study was neither fixed nor counterbalanced. In fact, there was only one manipulation that two monkeys (S-200 and S-464) shared in the same order (the light stimulus was omitted after four baseline sessions and reinstated afterwards). Out of a total of 18 manipulations in this study, three consisted of two sessions, five of four sessions, one of five sessions, three of six sessions, one of seven sessions, two of nine sessions, two of ten sessions and one of eleven sessions. The length of the manipulations seems to have been determined ad hoc by whether the results were in the predicted direction. In the above example of omitting the light stimulus, one monkey was run for seven sessions and the other for eleven sessions before the light stimulus was reinstated. The experimenters must have waited until each monkey was at a visible low point, and then stopped (thus eliminating the risk that the response rate would increase again). The same pattern was repeated when the light was reinstated. The first monkey returned to baseline levels after 5 sessions, at which point observations were stopped (thereby avoiding the risk of a later reduction in the rate of pressing). In contrast, the second animal was observed for 11 sessions, until it finally returned to its baseline levels. ${ }^{1}$

In summary, the study that purportedly provided a "conclusive demonstration" that nicotine can function as an efficacious positive reinforcer (US Department of Health and Human Services, 1988) relied on a total of four monkeys, of which only two were subjected to the critical manipulations, with no control for general activation, no standardization of procedure, no statistical tests of the results or even numerical summaries of the data, and no consideration of alternative explanations of the findings.

\footnotetext{
${ }^{1}$ We conducted a statistical analysis to confirm the apparent relationship between the animal's cooperation with the experimental hypotheses and the number of sessions that animal was observed. For each manipulation, we computed a 'favorable change index,' using the difference in pressing rates (in the direction predicted by the authors) between the last session of the prior condition and the second session of the present manipulation. The Spearman rank correlation between this index and the number of sessions the researchers allowed for the manipulation $-0.72(p<0.05)$, confirming that smaller changes in the expected direction were significantly related to a larger number of sessions.
} 


\section{Limitations of Recent Studies (1989-2000)}

A year following the Surgeon General's report, a new method of nicotine self-administration in the rate was described by Corrigall and Coen (1989). According to the authors, the new method resulted in relatively high, stable, and dose-dependent rates of responding, without the use of concurrent additional reinforcement or nicotine pretreatment. Corrigall and Coen's procedure was replicated many times by their group and several others (e.g., Corrigall and Coen, 1991a,b, 1994; Corrigall et al., 1992, 1994; Donny et al., 1995, 1998; Tessari et al., 1995; Chiamulera et al., 1996; Pagliusi et al., 1996; Pich et al., 1997, 1998; Shaham et al., 1997; Bardo et al., 1999; Watkins et al., 1999). Nevertheless, the procedure suffers from major methodological flaws that compromise any conclusions that could be drawn from it. As this procedure is widely considered to have established nicotine self-administration (and hence nicotine addiction) in rats, its limitations deserve detailed analysis.

\section{Food Deprivation}

According to Corrigall and Coen's method, rats are food deprived for $36 \mathrm{~h}$, and then trained to press a lever for food pellets on a continuous reinforcement schedule (FR1). Once trained, animals are fed their daily nutrient requirement of standard lab chow as a single meal $(20 \mathrm{~g})$. Following training, an intravenous catheter is implanted in the rats and they are placed in an operant chamber for $1 \mathrm{~h}$ each day. The animals have access to the same lever they had learned to press under previous training conditions, but rather than receiving a food pellet as a reinforcement, they receive an injection of nicotine solution. The other training conditions are also maintained. Specifically, the animals continue to be fed $20 \mathrm{~g}$ of food following the session, which is about half of what they would eat if they had free access to food (Donny et al., 1998). They cannot eat again until after the next session, at least $20 \mathrm{~h}$ later. Thus, as Corrigall and Coen (1989) acknowledged, the rats are not only food deprived throughout the study, but are particularly hungry during the nicotine selfadministration sessions. 
Food deprivation has been known for over two decades to facilitate nicotine self-administration in rats (e.g., Lang et al., 1977; Singer et al., 1978; Dougherty et al., 1981). A more recent demonstration was provided by Watkins et al. (1999), who used basically the same method as Corrigall and Coen (1989) for training the animals, but fed their animals ad libitum when pressing for nicotine. This had a dramatic effect on self-administration: in one of their experiments, only 6 out of 17 rats self-administrated nicotine. When the animals were returned to the restrictive feeding schedule, 14 out of 17 selfadministered nicotine. These findings suggest that the critical factor in Corrigall and Coen's (1989) procedure is hunger rather than nicotine. Animals that were trained to press a lever for food will continue to do so whenever they are hungry. This is not surprising, as in Corrigall and Coen's procedure, animals do not undergo an extinction period before they are switched to nicotine. As Donny et al's (1998) study demonstrated, prior operant conditioning with food reinforcement can sustain bar pressing in hungry animals in the absence of nicotine or food for at least nine days. This finding suggests that the reinforcing properties of food for hungry animals can be transferred, by classical conditioning, to the lever. The secondary reinforcing properties of the lever can later be conditioned to any recognizable stimulus property of nicotine and make its injection reinforcing.

This hypothesis is supported by the observations of Shaham and his coauthors (1997) that following a priming injection of nicotine, acutely food-deprived rats, trained to self-administer nicotine and then subsequently extinguished, display not only nicotine-seeking but also food-seeking behavior. Together, these studies suggest that selfadministration of nicotine in Corrigall and Coen's (1989) paradigm may be partially attributable to secondary reinforcing properties that nicotine acquires by classical conditioning to food.

The possibility that hunger is the crucial factor that maintains nicotine self-administration in Corrigall and Coen's paradigm is also consistent with the anorectic properties of nicotine in rats, which were demonstrated within the dose range self-administered by rats in a daily session (e.g., Caggiula et al., 1991; Schwid et al., 1992; Zarrindats and Oveisi, 1997). This anorectic effect would well be a sufficiently powerful negative reinforcer to sustain responding, even if nicotine would have no reinforcing properties in any other condition. 


\section{Confounding Reinforcement with Activation}

In several studies that employed Corrigall and Coen's procedure (e.g., Donny et al., 1995,1998; Tessari et al., 1995; Bardo et al., 1999), rats were submitted to fixed ratio (noncontinuous) schedules of reinforcement. These schedules (FR2 and FR5) generally led to an increase in responding, which was taken as evidence for the reinforcing properties of nicotine. A recent study by Bardo and coworkers (Bardo et al., 1999), however, demonstrates that this conclusion is dubious. As in similar studies, rats were allowed a number of days (five, in this case) on an FR1 schedule before switching to higher ratio schedules. Rather than increased responding over these five days, which would indicate learning, rats showed a reduction in responses until day 5. More importantly, response rates were not noticeably different from the response rates for saline during these five days. Thus, by these two criteria, when animals were on the FR1 schedule, nicotine did not act as a reinforcer. However, when animals were switched for two days to an FR2 and for 5 days to an FR5 schedule, lever-pressing rate increased two-fold and five-fold, respectively. This finding is puzzling: how could nicotine be reinforcing in FR2 and FR5 schedules, but not in the continuously reinforced (FR1) schedule?

A possible answer to this puzzle is suggested by another experiment by the same group of investigators (Dwoskin et al., 1999). In this study, a $0.3-1.0 \mathrm{mg} / \mathrm{kg}$ dose of nicotine, which is pharmacologically similar to the one self-administered in the previous study (about $0.6 \mathrm{mg}$ per session), produced a depression of locomotion at the first daily session, but enhanced locomotion by Day 8 . It is therefore very plausible that the rats that self-administered nicotine in the previous study became increasingly activated (and hence pressed more) following daily exposures to nicotine, in a timeframe that corresponded to shifting the animals to FR2 and FR5 schedules. This increased activation, rather than the presumably rewarding quality of nicotine, can fully account for the increased lever-pressing rate found at the higher reinforcement schedules. With the exception of two studies we shall described below (Donny et al., 1998, 2000), this crucial confound has not been controlled for by any of the studies using Corrigall and Coen's procedure. 


\section{Elimination of Uncooperative Subjects}

The original study that made Corrigall and Coen's procedure popular (Corrigall and Coen, 1989) did not employ any systematic control for the effects of weight and food restriction on nicotine selfadministration. The first attempt to validate Corrigall and Coen's model by submitting it to systematic, critical, and well-controlled experimentation was undertaken by Donny and his colleagues nine years later (Donny et al., 1998). As the findings of this study were interpreted by the authors as validating Corigall and Coen's paradigm, it is important to examine it closely.

Donny and his colleagues conducted three separate studies, designed to examine the effects of nicotine dose, feeding schedule and drug contingency on lever pressing (and consequent nicotine infusion) in Corigall and Coen's (1989) procedure. In the first study, they showed that rats trained according to this procedure self-administered nicotine at doses of 0.03 and $0.06 \mathrm{mg} / \mathrm{kg}$ per infusion. Nicotine selfadministration was defined as a statistically significant difference between the frequencies of pressing on the active as compared to the inactive lever. However, these significant differences were obtained on a biased subsample of the rats: animals that did not achieve stable nicotine self-administration were excluded from analysis. In the $0.06 \mathrm{mg} / \mathrm{kg}$ dose, one third of the rats were excluded from the reported results; for the $0.03 \mathrm{mg} / \mathrm{kg}$ dose, $40 \%$ of the rats were excluded. The authors stated that "the same pattern of result was found when all animals were included in the analyses, indicating that the results are not a function of an arbitrary acquisition criterion" (Donny et al., 1998, p. 85). However, this "pattern" is not presented, and it is doubtful that the statistical analyses would have produced the same results; otherwise, there would have been no need to exclude the uncooperative subjects.

The practice of excluding animals that do not meet the desirable performance criteria from data analysis and from the reported results seems to be the rule in this paradigm (e.g., Corrigall and Coen, 1991a,b, 1994; Donny et al., 1995; Shaham et al., 1997; Bardo et al., 1999; Shoaib and Stolerman, 1999; Watkins et al., 1999). Whether this was also done by other groups is often unclear (e.g., Corrigall et al., 1992; Chiamulera et al., 1996; Pagliusi et al., 1996). Discarding 
animals from analyses may be valid for questions pertaining only to the subpopulation of self-administering animals. Shaham et al. (1997), for example, investigated the 'relapse' of rats following the extinction of nicotine self-administration and a priming injection of nicotine. This study cannot be performed in rats that did not self-administer nicotine in the first place. Exclusion of uncooperative animals is clearly not appropriate, however, when the research question is whether or not rats self-administer nicotine. This practice can radically distort reality when as many as half of the animals are excluded for failing to acquire nicotine self-administation (e.g., Shoaib and Stolerman, 1999). Yet, experiments where uncooperative subjects were excluded are routinely cited as evidence for nicotine self-administration in rats, and are counted as replications of the original, 1989 experiment by Corrigall and Coen (e.g., Tobacco Advisory Group of The Royal College of Physicians, 2000, p. 48). As noted earlier, excluding animals that do not self-administer nicotine (about half of the population) and then proceeding to draw general conclusions appears to be an accepted norm in oral self-administration studies as well (e.g., Glick et al., 1998).

In their second experiment, Donny and his coauthors (Donny et al., 1998) examined the effect of food and weight restriction on lever pressing and the resultant amount of self-administered nicotine. The results confirmed that the practice of restricting the animal's diet and depriving them of food for more than $20 \mathrm{~h}$ prior to each session are crucial factors in this paradigm. Animals that had unlimited access to food during the nicotine sessions pressed the lever about 3 times less, and self-administered about one-third nicotine, compared to the animals that were food-deprived and weight-restricted. Despite this overwhelming effect, the authors concluded that "SA is not dependent on deprivation and/or weight restriction," as "rats in all feeding conditions demonstrated clear evidence of nicotine selfadministration (p. 88)." The claim is problematic, as the extent to which rats demonstrated evidence of nicotine self-administration depended very significantly on food deprivation. Presumably, the authors meant that while food deprivation greatly facilitates selfadministration, it is not absolutely essential for its occurrence. But even this weaker proposition cannot be justified: As in other experiments in this paradigm, the statistically significant effect of 
active $v s$ inactive lever pressing for the nondeprived group was achieved after $40 \%$ of the rats that failed to meet self-administration criteria were excluded from analysis.

\section{Lack of Saline Control Groups}

A critical flaw in the two experiments described above, and for that matter, in almost all the studies that used Corrigall and Coen's procedure, is the omission of a saline control condition. A saline control group, treated identically to the nicotine self-administering group, is essential for concluding that nicotine increases lever-pressing rates in this paradigm. Instead of a saline control condition, Donny et al. (1998), like other researchers using Corrigall and Coen's procedure, considered responding on the inactive lever as their control. Pressing on this inactive lever, however, never produces reinforcement for the animal in this procedure - neither when it is trained with food reward, nor in later stages. Consequently, animals in this procedure learn that pressing the inactive lever has no consequences, and demonstrate this knowledge by rarely touching it. Presses on the inactive lever, therefore, cannot be regarded as a measure of nonspecific activation and certainly not as indicating extinction of pressing for food reward. This critique can be evaluated empirically. Instead of training all the animals to press for nicotine on same lever earlier reinforced by food (the "active lever"), half the sample can be trained to press for nicotine on the second ("inactive") lever, using a counterbalanced design. With this procedure, overall differences between the nicotine reinforced lever and the second, nonreinforced lever would not be confounded with prior learning.

The vital necessity of saline control in this paradigm is underlined by the study of Bardo and his coworkers mentioned above (Bardo et al., 1999). These researchers used the same procedure as Donny and his coauthors but also had a control group pressing for saline injections. During the first 5 days of training in an FR1 schedule, there was no observable difference between the saline- and the nicotine-reinforced group. Therefore, any lever pressing that occurred during this phase of self-administration is entirely attributable to lack of extinction of pressing for food reward, rather to any effect of nicotine. It is unlikely that this effect of prior conditioning could have been observed if presses 
on an inactive lever, rather than a saline condition, had been used as the control for the nicotine condition in this study.

The third experiment of Donny et al. (1998) (see also Shaham et al. 1997) corroborated the role of conditioning to food reward in this paradigm and simultaneously demonstrated that the inactive lever is invalid as a control for any relevant experimental manipulation. In this experiment, saline control animals pressed approximately 25 times during the first session and did not demonstrate complete extinction when compared to presses on the inactive lever even by the end of the 9 days of the study.

In summary, the omission of saline control groups, combined with the practice of excluding one-third to one-half of the animals that do not acquire nicotine self-administration, invalidates any conclusions that can be drawn from Donny et al.'s first two experiments, as well as from most other studies in the same paradigm (e.g., Corrigall and Coen, 1991a, 1994; Donny et al., 1995; Shaham, et al., 1997; Shoaib and Stolerman, 1999; Watkins et al., 1999), regarding the reinforcing properties of nicotine.

\section{Unreliable Drug Contingency Effects}

The third experiment in Donny et al. (1998), which was just mentioned above, was designed to examine the effects of drug contingency on lever pressing for nicotine. Each rat that was run in the usual procedure had two yoked controls, for which infusion was not contingent on lever pressing. Every time the experimental animal pressed a lever, one yoked animal received a nicotine infusion identical to the self-administered one, and the other received an infusion of saline solution. In this experiment, the self-administering group pressed the lever significantly more than the two yoked control groups, which did not differ between them and in which responses declined over the nine days of the study.

Although the study is well designed, several anomalies compromise the validity of its results. First, there was no evidence in this experiment of the general activation effects of nicotine, which would have been expressed in a higher rate of lever pressing overall in the yoked nicotine group as compared to the yoked saline group, especially during the later 
phases of the study. This lack of general activation effect is peculiar in light of the studies cited above (e.g., Cox et al., 1984; Valentine et al., 1997), in which nicotine-administering animals showed considerable elevations in both active and inactive lever pressing. Second, the selfadministering rats pressed twice as many times as the other two groups in the very first session. As lever pressing in the first session is mostly determined by prior conditioning to food reward, this finding is quite unexpected and suggests that the results of this experiment reflect initial differences between the three groups. Third, the contingency group in this experiment, from which no animals were discarded, pressed nearly twice as many times as contingency groups in the two earlier experiments, where up to $40 \%$ of the animals were discarded for not meeting the criterion. This observation is consistent with the possibility that the contingency group in this particular experiment was anomalous, and its higher pressing rate reflects initial differences rather the reinforcing effects of nicotine.

Compelling evidence that the results of the experiment described above are indeed anomalous comes from a more recent experiment by the same group (Donny et al., 2000). In this study, which employed the same design as its predecessor (Donny et al., 1998), animals in both the contingent and the noncontingent nicotine condition pressed the lever more than the saline group. More importantly, there were no differences between the nicotine contingent and noncontingent groups; in fact, the noncontingent animals tended to press the lever more than the contingent animals. This finding clearly contradicts the accepted claim that lever presses in this paradigm are a function of the reinforcing effects of nicotine. While the authors acknowledge that their results may reflect nicotine's direct locomotor effects or its effect on rate of extinction, they refrain from raising the possibility suggested by this review, namely that these noncontingent effects provide a viable alternative account for the results obtained in all nicotine self-administration studies.

\section{Other Recent Animals Self-administration Studies}

As stated earlier, the study by Donny and his coworkers (Donny et al., 1998) seems to have been the only attempt to validate Corrigall and 
Coen's model. The vast majority of the experiments performed after 1989 were not designed to test whether animals self-administer nicotine because of its reinforcing properties. Instead, they were designed to test further manipulations on what were assumed to be the reinforcing properties of nicotine in rats (e.g., Chiamulera et al., 1996; Pagliusi et al., 1996; Pich et al., 1997), monkeys (Sannerud et al., 1994; Wakasa et al., 1995), and mice (Martellotta et al., 1995). Generally, investigators in this field seem to believe that the issue has been settled, despite the lack of studies that convincingly reject any of the multiple alternative hypotheses.

A recent study with mice employed a different procedure from that of Corrigall and Coen's. Stolerman et al. (1999) trained water-deprived mice to press a lever for water, and then switched them to intravenous nicotine. Animals self-administered first a higher dose of nicotine, than a lower dose, and finally saline, each for six daily sessions. The authors observed a significant increase in responses over the six days of the higher dose, a significant decrease over the six days of the lower dose, and no change over the six days that the animals received saline.

Unfortunately, this design also suffers from methodological problems. The order of the nicotine dose was not counter-balanced, so it was completely confounded with the time factor. Consequently, any changes with the nicotine dose may be attributable to the effects of time on memory, activation or suppression of motor responses, and most importantly, on extinction. Furthermore, only the high dose of nicotine, which was administered immediately following training with water reward, was significantly different from saline, and even this effect was obtained only by omitting the first three days of each dose from the analysis. In fact, saline maintained responding for six days, without any decline in response rate, at levels that were indistinguishable from the lower nicotine dose. Thus, the results of this study are fully accounted for by the effects of nicotine on activation together with the secondary reinforcing properties that nicotine was expected to acquire from the water reward.

Two other studies with mice demonstrated a more careful approach to experimental design and control (Martellotta et al., 1995; Rasmussen and Swedberg, 1998). These investigators had mice nose-poke for injections. The animals were placed in a confining 
experimental chamber with their tails outside. The tail was prepared with an intravenous catheter and fixed to the floor with adhesive tape. The only behavior the animals could perform was poking their nose through an opening in the wall. Half of the animals received an injection of nicotine or saline contingent on nose-poking, while the other half served as yoked controls, receiving the injection whenever their active partner nose poked.

In both studies, the contingent animals poked significantly more than the yoked controls on two doses of nicotine. While these results suggest that nicotine is reinforcing to immobilized mice, several factors limit their scope. First, nose-poking is a natural behavior in rodents. As lever pressing is a learned behavior, it provides a better measure of reinforcement. Second, immobilizing is a manipulation that increases stress in mice (e.g., Van der Heyden et al., 1997; Chesnokova et al., 1998; Sugimoto et al., 1998) and more studies will have to be conducted to see whether stress is a necessary condition for these effects. Third, baseline or control levels of nose poking reported for other groups (e.g., of cocaine and epibatidine) were nearly as high as the poking rates induced by nicotine (Rasmussen and Swedberg, 1998). Finally, it is somewhat puzzling that the reinforcing effects of nicotine did not require learning in this paradigm, and that no general activating effects were observed. However, in contrast to the great majority of nicotine self-administration studies, these studies are well performed and the results are more convincing. To date, these seem to be the only wellcontrolled studies in which animals that were neither food deprived nor trained on other reinforcements initiated self-administration of nicotine.

\section{NICOTINE AND DOPAMINE OVERFLOW: THE "ANHEDONIA HYPOTHESIS"}

For nearly two decades, there was little doubt that mesolimbic and mesostriatal dopamine release was equivalent to reward. This dominant view was expressed in the 'anhedonia' hypothesis, formulated by Wise and his coworkers (Fouriezos and Wise, 1976; Fouriezos et al., 1978; Wise et al., 1978; Wise, 1982) which proposed that these dopamine systems mediated pleasure. When dopamine antagonists 
are administered to animals, according to this hypothesis, "all of life's pleasures - the pleasures of primary reinforcement and the pleasures of their associated stimuli - lose their ability to arouse the animal (Wise, 1982, p. 52)." Thus, dopamine was believed to mediate the pleasure of food, sex, and drugs of abuse.

As the 'anhedonia' hypothesis essentially equated dopamine release with reward, it lent itself to a simple and foolproof test of the rewarding properties of drug: if a drug produces an increase in dopamine, it must be rewarding. According to this criterion, nicotine was clearly rewarding, as it was consistently reported to increase release of dopamine in the nucleus accumbens (e.g., Imperato et al., 1986; Clarke et al., 1988; Pontieri et al., 1996; Pich et al., 1997; Glick et al., 1998; Reid et al., 1998; Schilstrom et al., 1998), apparently by exciting ventral tegmental neurons (Calabresi et al., 1989; Pidoplichko et al., 1997; Fischer et al., 1998; Louis and Clarke, 1998; Schilstrom et al., 1998).

Evidence accumulated in recent years, however, has unequivocally refuted the assumption that dopamine release equals reward. As Gray and his colleagues (Gray et al., 1997) stated, "This evidence shows that unpleasant events such as foot-shock increase extra-cellular levels of dopamine in the nucleus accumbens, as measured for example, by in vivo intra-cerebral microdialysis. (...) We believe, in the light of findings such as these, that there is no special relationship between dopamine release in the nucleus accumbens and positive reinforcement (pp. 1548-1549)." Or, in the words of Berridge and Robinson (1998): "There can be no doubt that behavior needed to actively avoid an unpleasant outcome is impaired as strongly by dopamine suppression as behavior directed toward a positive reward (p. 348, emphasis in original)." Aversive events such as foot-shock (Sorg and Kalivas, 1991), forced exercise (D'Angio et al., 1990), tail pinch stress (D'Angio et al., 1987), restraint stress (Imperato et al., 1986, 1992) and others (for review, see Joseph et al., 1996; Salamone et al., 1997) have all been shown to increase dopamine release in the nucleus accumbens.

There is little agreement amongst current researchers on the role of dopamine in reward. It has been argued that dopamine release in the nucleus acumbens is correlated with the novelty of the stimulus (e.g., Revec et al., 1997; Garris et al., 1999), the relevance of the stimulus (Joseph et al., 1996), reward learning (e.g., Beninger, 1983; White, 
1989; Cohen and Servan-Schreiber, 1993; Aosaki et al., 1994, 1995; Montague et al., 1996; Schultz, 1997; Schultz, et al., 1997; DiChiara, 1998), and "wanting" (but not "liking") and event in the "incentive salience" theory (Berridge and Robinson, 1998).

It is not within the scope of this review to evaluate these theories. Our goal in this brief summary is only to stress that the observation that nicotine causes the release of dopamine in mesolimbic and mesostriatal structures does not prove that is has reinforcing properties. Rather, depending on circumstances, it may indicate that nicotine is aversive, or novel, or somehow involved in learning processes. Dopamine release cannot be taken as a reliable indication that nicotine, or any other psychoactive drug, is rewarding.

\section{HOW CAN NICOTINE'S REINFORCING PROPERTIES BE ESTABLISHED OR REFUTED?}

There are two types of self-administration paradigms that hold the promise of determining whether nicotine is reinforcing in animals. The more powerful paradigm is the one used by Cox et al. (1984) and Valentine et al. (1997), with the addition of essential controls. In this paradigm, nonprimed animals are individually housed in operational chambers with food and water ad libitum. They have continuous access to one lever delivering either i.v. nicotine or saline on a CRS. Both groups have two yoked controls - one receiving saline, the other the same dose of nicotine that the contingent rats receive. Needless to add, none of the subjects should be discarded from the analyses. We would expect that none of the saline groups would show increases in lever pressing. If the nicotine contingent rats increase lever pressing and their yoked nicotine controls do not, nicotine's reinforcing properties would be demonstrated both in initiating and in maintaining self-administration. If the yoked controls press at the same or higher rates than the nicotine contingent animals, this would constitute evidence that any increase in lever pressing results from general activation, and that nicotine is not reinforcing in this paradigm.

Corrigall and Coen's (1989) basic paradigm is less powerful as it can only demonstrate that nicotine is capable of maintaining lever pressing. 
But even that requires a saline control group for nicotine rather than an inactive lever (see Bardo et al., 2000). Only CRF schedules should be used to avoid additional confounds that may be introduced with higher schedules (e.g., if nicotine were aversive to the animal, its activating properties would conflict with its aversive properties; this would lead to a higher frequency of presses in higher schedules, in the animals is less frequently "punished" for bar presses). Yoked controls should be added to control for time-dependent noncontingent activation, and no subjects should be eliminated from analyses. This is exactly the design used by Donny et al. (2000), however, and as discussed above, in that study the nicotine noncontingent animals pressed at least as frequently as the nicotine contingent ones. Thus, the best controlled study to date using this paradigm provides no support for the thesis that self-administration is maintained by the reinforcing properties of nicotine.

\section{CONCLUSION}

This review indicates that self-administration studies have not established that nicotine is a positive primary reinforcer in animals. The great majority if these studies suffer form severe methodological flaws, which compromise both their internal and their external validity. The internal validity of these studies, that is, the extent to which they reliably produce nicotine self-administration, was compromised by (1) a lack of appropriate comparison groups, particularly saline and yoked controls; (2) partial presentation of results and absence of statistical tests; (3) lack of standardization and ad hoc methodological decisions. The external validity of these studies, that is, the extent to which their results can be attributed to the reinforcing properties of nicotine, is limited due to (1) lack of control for general activation, anorectic properties and other systemic effects of nicotine; (2) insufficient consideration of secondary reinforcement processes; (3) using food-deprived or confined animals; and (4) exclusion of subjects that do not conform to the investigators' preferred behavior. While some new studies show more promise, we conclude that the role of nicotine as a primary reinforcer in animals remains to be established. As discussed above, this conclusion undermines the validity 
of the nicotine addiction thesis, with important implication to the understanding and treatment of smoking.

\section{References}

Aosaki, T., Graybiel, A.M. and Kimura, M. (1994). Effect of the nigrostriatal dopamine system on acquired neural responses in the striatum of behaving monkeys. Science, 265, 412-415.

Aosaki, T., Kimura, M. and Graybiel, A.M. (1995). Temporal and spatial characteristics of tonically active neurons of the primate's striatum. Journal of Neurophysiology, 73, 1234-1252.

Aravich, P.F., Stanley, E.Z. and Doerries, L.E. (1985). Exercise in food-restricted rats produces 2DG feeding and metabolic abnormalities similar to anorexia nervosa. Physiology and Behavior, 57, 147-153.

Arnold, B.K., Allison, S.I., Paetsch, T.P. and Greenshaw, A.J. (1995). 5HT3 receptor antagonists do not block nicotine induced hyperactivity in rats. Psychopharmacology, 199, 213-221.

Ator, N.A. and Griffiths, R.R. (1983). Nicotine self-administration in baboons. Pharmacology Biochemistry and Behavior, 19, 993-1003.

Atrens, D.M. (2001). Nicotine as an addictive substance: a critical examination of the basic concepts and empirical evidence. Journal of Drug Issues, 31, 325-394.

Bandura, A., Adams, N.E., Hardy, A.B. and Howells, G.N. (1980). Tests of the generality of self-efficacy theory. Cognitive Therapy and Research, 4, 39-66.

Bardo, M.T., Green, T.A., Crooks, P.A. and Dwoskin, L.P. (1999). Nornicotine is selfadministered intravenously by rats. Psychopharmacology, 146, 290-296.

Battig, K., Driscoll, P., Schlatter, J. and Uster, H.J. (1976). Effects of nicotine on the exploratory locomotion patterns of female roman high- and low-avoidance rats. Pharmacology Biochemistry and Behavior, 4, 435-439.

Beninger, R.J. (1983). The role of dopamine in locomotor activity and learning. Brain Research, 287, 173-196.

Berridge, K.C. and Robinson, T.E. (1998). What is the role of dopamine in reward: Hedonic impact, reward leraning, or incentive salience? Brain Research Reviews, 28, 309-369.

Bozarth, M.A. and Wise, R.A. (1985). Toxicity associated with long-term intravenous heroin and cocaine self-administration in the rat. Journal of the American Medical Association, 254, 81-83.

Brioni, J.D., Kim, D.J.B., O'Neill, A.B., Williams, J.E.G. and Decker, M.W. (1994). Clozapine attenuates the discriminative stimulus properties of (-)-nicotine. Brain Research, 643, 1-9.

Caggiula, A.R., Epstein, L.H., Antelman, S.M., Saylor, S.S., Perkins, K.A., Knopf, S. and Stiller, R. (1991). Conditioned tolerance to the anorectic and corticosteroneelevating effects of nicotine. Pharmacology Biochemistry and Behavior, 40, 53-59.

Calabresi, P., Lacey, M.G. and North, R.A. (1989). Nicotine excitation of rat ventral tegmental neurones in vitro studied by intracellular recording. British Journal of Pharmacology, 98, 135-140.

Chance, W.T., Murfin, D., Krynock, G.M. and Rosecrans, J.A. (1977). A description of the nicotine stimulus and tests of its generalization to amphetamine. Psychopharmacology, 55, 19-26.

Chesnokova, V., Auernhammer, C.J. and Melmed, S. (1998). Murine leukemia inhibitory factor gene disruptiona attenuates the hypothalamo-pituitary-adrenal axis stress response. Endocrinology, 139, 2209-2216. 
Chiamulera, C., Borgo, C., Falchetto, S., Valerio, E. and Tessari, M. (1996). Nicotine reinstatement of nicotine self-administration after long-term extinction. Psychopharmacology, 127, 102-107.

Clarke, P.B., Fu, D.S., Jakubovic, A. and Fibiger, H.C. (1988). Evidence that mesolimbic dopaminergic activation underlies the locomotor stimulant action of nicotine in rats. Journal of Pharmacology and Experimental Therapeutics, 246, 701-708.

Clarke, P.B. and Kumar, R. (1983a). Characterization of the locomotor stimulant action of nicotine in tolerant rats. British Journal of Pharmacology, 80, 587-594.

Clarke, P.B. and Kumar, R. (1984). Effects of nicotine and d-amphetamine on intracranial self-stimulation in a shuttle box test in rats. Psychopharmacology, 84, 109-114.

Clarke, P.B.S. and Kumar, R. (1983b). Nicotine does not improve discrimination of brain stimulation reward by rats. Psychopharmacology, 79, 271-277.

Clarke, P.B.S. and Kumar, R. (1983c). The effects of nicotine on locomotor activity in non-tolerant and tolerant rats. British Journal of Pharmacology, 78, 329-337.

Cohen, J.D. and Servan-Schreiber, D. (1993). A theory of dopamine function and its role in cognitive deficits in schizophrenia. Schizophrenia Bulletin, 19, 85-104.

Corrigall, W.A., Clarke, P.B., Coen, K.M. and Franklin, K.B.J. (1992). The mesolimbic dopaminergic system is implicated in the reinforcing effects of nicotine. Psychopharmacology, 107, 285-289.

Corrigall, W.A. and Coen, K.M. (1989). Nicotine maintains robust self-administration in rats on a limited-access schedule. Psychopharmacology, 99, 473-478.

Corrigall, W.A. and Coen, K.M. (1991a). Opiate antagonists reduce cocaine but not nicotine self-administration. Psychopharmacology, 104, 167-170.

Corrigall, W.A. and Coen, K.M. (1991b). Selective dopamine antagonists reduce nicotine self-administration. Psychopharmacology, 104, 171-176.

Corrigall, W.A. and Coen, K.M. (1994). Nictoine self-administration and locomotor activity are not modified by the 5-HT3 antagonists ICS 205-930 and MDL 72222. Pharmacology Biochemistry and Behavior, 49, 67-71.

Corrigall, W.A., Coen, K.M. and Adamson, K.L. (1994). Self-administered nicotine activates the mesolimbic dopamine system through the ventral tegmental area. Brain Research, 653, 278-284.

Corrigall, W.A., Franklin, K.B., Coen, K.M. and Clarke, P.B. (1992). The mesolimbic dopaminergic system is implicated in the reinforcing effects of nicotine. Psychopharmacology, 107, 285-289.

Cox, B.M., Goldstein, A. and Nelson, W.T. (1984). Nicotine self-administration in rats. British Journal of Pharmacology, 83, 49-55.

D'Angio, M.B., Serrano, A., Rivy, J.P. and Scatton, B. (1987). Tail pinch stress increases extracellular DOPAC levels (as measured by in vivo voltammetry) in rat nucleus accumbens but not frontal cortex: antagonism by diazepam and zolpidem. Brain Research, 409, 169-174.

D'Angio, M.B. Serrano, A. Scatton, B. and Scatton, J.P. (1990). Mesocorticolimbic dopaminergic systems and emotional states. Journal of Neuroscience Methods, 34, 135-142.

Davis, C. (1997). Eating disorders and hyperactivity: a psychobiological perspective. Canadian Journal of Psychiatry, 42, 168-175.

Davis, C. and Claridge, G. (1998). The eating disorders as addiction: a psychobiological perspective. Addictive Behaviors, 23, 463-475.

Davis, C., Kennedy, S.H., Ravelski, E. and Dionne, M. (1994). The role of physical activity in the development and maintenance of eating disorders. Psychological Medicine, 24, 957-967.

De La Garza, R., and Johanson, C.E. (1987). The effects of food deprivation on the selfadministration of psychoactive drugs. Drug and Alcohol Dependence, 19, 17-27.

DiChiara, G. (1998). A motivational learning hypothesis of the role of mesolimbic dopamine in compulsive drug use. Journal of Psychopharmacology, 12, 54-67. 
Donny, E.C., Caggiula, A., Rose, C., Jacobs, K.S., Mielke, M.M. and Sved, A.F. (2000). Differential effects of response-contingent and response-independent nicotine in rats. European Journal of Pharmacology, 402, 231-240.

Donny, E.C., Caggiula, A.R., Knopf, S. and Brown, C. (1995). Nicotine self-administration in rats. Psychopharmacology, 122, 390-394.

Donny, E.C., Caggiula, A.R., Mielke, M.M., Jacobs, K.S., Rose C. and Sved, A.F. (1998). Acquisition of nicotine self-administration in rats: the effect of dose, feeding schedule and drug contingency. Psychopharmacology, 136, 83-90.

Dougherty, J., Miller, D., Todd, G. and Kostenbauder, H.B. (1981). Reinforcing and other behavioral effects of nicotine. Neuroscience and Biobehavioral Reviews, 5, 487-495.

Dwoskin, L.P., Crooks, P.A., Teng, L. Green, T.A. and Bardo, M.T. (1999). Acute and chronic effects on locomotor activity in rats: altered response to nicotine. Psychopharmacology, 145, 442-451.

Eiser, J.R. and van der Plight, J. (1986). Smoking cessation and smokers' perception of their addiction. Journal of Social and Clinical Psychology, 4, 60-70.

Eiser, J.R., van der Plight, J. Raw, M. and Sutton, S.R. (1985). Trying to stop smoking: effects of perceived addiction, attribution for failure, and expectancy of success. Journal of Behavioral Medicine, 8, 321-341.

Fischer, J.L., Pidoplichko, V.I. and Dani, J.A. (1998). Nicotine modifies the activity of ventral tegmental area dopaminergic neurons and hippocampal GABAergic Neurons. Journal de Physiologie (Paris), 92, 209-213.

Flynn, F.W., Webster, M. and Ksir, C. (1989). Chronic voluntary nicotine drinking enhances nicotine palatability. Behavioral Neuroscience, 103, 356-364.

Fouriezos, G., Hansson, P. and Wise, R.A. (1978). Neuroleptic-induced attenuation of brain stimulation reward in rats. Journal of Comparative and Physiological Psychology, 92, 661-671.

Fouriezos, G. and Wise, R.A. (1976). Pimozide-induced extinction of intracranial selfstimulation: response patterns rule out motor or performance deficits. Bain Research, 103, 377-380.

Frenk, H. and Dar, R. (2000). A Critique of Nicotine Addiction. Kluwer Academic Publishers, Boston.

Fung, Y.K. (1990). The important of the nucleus accumbens in nicotine-induced locomotor activity. Journal of Pharmacy and Pharmacology, 42, 595-596.

Garris, P.A., Kilpatrick, M., Bunin, M.A., Michael, D., Walker, Q.D. and Wightman, R.M. (1999). Dissociation of dopamine release in the nucleus accumbens from intracranial self-stimulation. Nature, 368, 67-69.

Glick, S.D., Maisonneuve, I.M., Visker, K.E., Fritz, K.A., Bandarage, U.K. and Kuehne, M.E. (1998). 18-Methoxycoronardine attenuates nicotine-induced dopamine release and nicotine preferences in rats. Psychopharmacology, 139, 274-280.

Glick, S.D., Visker, K.E. and Maisonneuve, I.M. (1996). An oral self-administration model of nicotine preference in rats: effects of mecamylamime. Psychopharmacology, 128, 426-431.

Goldberg, S.R. and Henningfied, J.E. (1983). Intravenous nicotine self-administration in humans and squirrel monkeys. Neuroscience Letters, 14(Supplement), S140.

Goldberg, S.R. and Hennningfield, J.E. (1988). Reinforcing effects of nicotine in humans and experimental animals responding under intermittent schedules of i.v. drug injection. Pharmacology Biochemistry and Behavior, 30, 227-234.

Goldberg, S.R., Risner, M.E., Stolerman, I.P., Reavill, C. and Garcha, H.S. (1989). Nicotine and some related compounds: effects on schedule-controlled behaviour and discriminative properties in rats. Psychopharmacology, 97, 295-302.

Goldberg, S.R. and Spealman, R.D. (1982). Maintenance and suppression of behavior by intravenous nicotine injections in squirrel monkeys. Federation Proceedings, 41, 216-220. 
Goldberg, S.R., Spealman, R.D. and Goldberg, D.M. (1981). Persistent behavior at high rates maintained by intravenous self-administration of nicotine. Science, 214, 573-575.

Gray, J.A., Young, A.M. and Joseph, M.H. (1997). Dopamine's role (letter). Science, 278, 1548-1549.

Griffiths, R.R., Brady, J.V. and Bradford, L.D. (1979). Predicting the abuse liability of drugs with animal drug self-administration procedures: psychomotor stimulants and hallucinogens. In: Thompson, T. and Dews, P.B. (Eds.), Advances in Behavioral Pharmacology, Vol. 2. Academic press, New York.

Hakan, T. (1988). Nictone-induced locomotor activity in rats. Pharmacology Biochemistry and Behavior, 29, 661-663.

Hanson, H.M. Ivester, C.A. and Morton, B.R. (1979). Nicotine self-administration in rats. NIDA Research Monographs, 70-90.

Harrington, G.M. (1979). Strain differences in light-contingent barpress behavior of the rat. Bulletin of the Psychonomic Society, 13, 155-156.

Helton, D.R., Modlin, D.L., Tizzano, J.P. and Rasmussen, K. (1993). Nicotine withdrawal: a behavioral assessment using schedule controlled responding, locomotor activity and sensorimotor reactivity. Psychopharmacology, 113, 205-210.

Henningfield, J.E. and Keenan, R.M. (1993). Nicotine delivery kinetics and abuse liability. Journal of Consulting and Clinical Psychology, 61, 743-750.

Hutchinson, R.R. and Emley, G.S. (1988). Aversive stimulation produces nicotine ingestion in squirrel monkeys. Psychological Records, 35, 491-502.

Imperato, A., Angelucci, L., Casolini, P., Zocchi, A. and Puglisi-Allegra, S. (1992). Repeated stressful experiences differently affect limbic dopamine release during and following stress. Brain Research, 557, 194-199.

Imperato, A., Mulus, A. and DiChiara, G. (1986). Nicotine preferentially stimulates dopamine release in the limbic system of freely moving rat. European Journal of Pharmacology, 132, 337-338.

Jenks, R.J. (1994). Attitudes and perceptions towards smoking: smokers' views of themselves and other smokers. Journal of Social Psychology, 134, 355-361.

Jerome, A. and Sandberg, P.R. (1987). The effects of nicotine on locomotor behavior in non-tolerant rats: a multivariate assessment. Psychopharmacology, 93, 397-400.

Joseph, M.H., Young, A.M.J. and Gray, J.A. (1996). Are neurochemistry and reinforcement enough- can the abuse potential of drugs be explained by common actions on a dopamine reward system in the brain? Human Psychopharmacology, 11, 55-63.

Kanarek, R.B. and Collier, G.H. (1983). Self-starvation: a problem of overriding the satiety signal? Physiology and Behavior, 30, 307-311.

Katz, R.C. and Singh, N.N. (1986). Reflections on the ex-smoker: some findings on successful quitters. Journal of Behavioral Medicine, 9, 191-202.

Kuschinsky, G. and Hotovy, R. (1943). Ueber die zentral errengende Wirkung des Nicotins. Klinische Wochenschrifte, 22, 649-650.

Lang, W.J., Latiff, A.A., Mcqueen, A. and Singer, G. (1977). Self administration of nicotine with and without a food delivery schedule. Pharmacology Biochemistry and Behavior, 7, 65-70.

Lau, C.E., Spear, D.J. and Falk, J.L. (1994). Acute and chronic nicotine effects on multiple-schedule behavior: oral and SC routes. Pharmacology Biochemistry and Behavior, 48, 209-215.

Lett, B.T. and Grant, V.L. (1996). Wheel running induces conditioned taste aversion in rats trained while hungry and thirsty. Physiology and Behavior, 59, 699-702.

Lett, B.T., Grant, V.L., Neville, L.L., Davis, M.J. and Koh, M.T. (1997). Chlordiazepoxide counteracts activity-induced suppression of eating in rats. Experimental Clinical Psychopharmacology, 5, 24-27. 
Louis, M. and Clarke, P.B. (1998). Effect of ventral tegmental 6-hydroxydopamine lesions on the locomotor stimulant action of nicotine in rats. Neuropharmacology, 37, 1503-1513.

Lynch, W.J. and Carroll, M.E. (1999). Regulation of intravenously self-administered nicotine in rats. Experimental and Clinical Psychopharmacology, 7, 198-207.

Martellotta, M.C., Kuzmin, A., Zvartau, E., Cossu, G., Gessa, G.L. and Fratta, W. (1995). Isradipine inhibits nicotine intravenous self-administration in drug-naive mice. Pharmacology Biochemistry and Behavior, 52, 271-274.

Martin, D.S. (1990). Physical dependence and attributions of addiction among cigarette smokers. Addictive Behaviors, 15, 69-72.

Martin, T.J., Dworkin, S.I. and Smith, J.E. (1995). Alkylation of mu opioid receptors by beta-funaltrexamine in vivo: comparison of the effects on the in situ binding and heroin self-administration in rats. Journal of Pharmacology and Experimental Therapeutics, 272, 1135-1140.

Montague, P.R., Dayan, P. and Sejnowski, T.J. (1996). A framework for mesencephalic dopamine systems based on predictive Hebbian learning. Journal of Neuroscience, 16, 1936-1947.

Morrison, C.F. (1967). Effects of nicotine on operant behavior of rats. International Journal of Neuropharmacology, 6, 229-240.

Morrison, C.F. and Stephenson, J.A. (1972). The occurrence of tolerance to a central depressant effect of nicotine. British Journal of Pharmacology, 45, 151-156.

Museo, E. and Wise, R.A. (1990). Locomotion induced by ventral tegmental microinjections of a nicotine agonist. Pharmacology Biochemistry and Behavior, 35, 735-737.

Myslobodsky, M. (1976). Petit Mal Epilepsy: A Search for the Precursors of Wave-Spike Activity. Academic Press, New York.

Nadal, R. and Samson, H.H. (1999). Operant ethanol self-administration after nicotine treatment and withdrawal. Alcohol, 17, 139-147.

Nishida, N. and Chiba, S. (1991). Intravenous self-administration of an enkephalin analog, EK-399, by rats. Journal of Toxicological Science, 16, 75-86.

O'Neill, M.F., Dourish, C.T. and Iversen, S.D. (1991). Evidence for an involvement of D1 and D2 dopamine receptors in mediating nicotine-induced hyperactivity in rats. Psychopharmacology, 104, 343-350.

Opitz, K. and Weischer, M.L. (1988). Volitional oral intake of nicotine in tupaias: druginduced alterations. Drug and Alcohol Dependence, 21, 99-104.

Owen, N.H. and Brown, S.L. (1991). Smokers unlikely to quit. Journal of Behavioral Medicine, 14, 627-636.

Pagliusi, S.R., Tessari, M., DeVevey, S., Chiamulera, C. and Pich, E.M. (1996). The reinforcing properties of nicotine are associated with a specific patterning of c-fos expression in the rat brain. European Journal of Pharmacology, 8, 2247-2256.

Pich, E.M., Chiamulera, C. and Tessari, M. (1998). Neural substrate of nicotine addiction as defined by functional brain maps of gene expression. Journal de Physiologie (Paris), 92, 225-228.

Pich, E.M., Pagliusi, S.R., Tessari, M., Talabot-Ayer, D., Hooft, van Huijsduijnen and Chiamulera, C. (1997). Common neural substrates for the addictive properties of nicotine and cocaine. Science, 275, 83-86.

Pidoplichko, V.I., DeBiasi, M., Williams, J.T. and Dani, J.A. (1997). Nicotine activates and desensitizes midbrain dopamine neurons. Nature, 390, 401-404.

Pirke, K.M., Broocks, A., Wilckens, T., Marquard, R. and Schweiger, U. (1993). Starvation-induced hyperactivity in the rat: the role of endocrine and neurotransmitter changes. Neuroscience and Biobehavioral Reviews, 17, 287-294.

Pontieri, F.E., Tanda, G., Orzi, F. and DiChiara, G. (1996). Effects of nicotine on the nucleus accumbens and similarity to those of addictive drugs. Nature, 382, 255-257.

Prada, J.A. and Goldberg, S.R. (1985). Effects of caffeine or nicotine pretreatments on nicotine self-administration by the squirrel monkey. Pharmacologist, 27, 226. 
Pradhan, S.N. (1970). Effects of nicotine on several schedules of behavior in rats. Archives of International Phamacodynamics, 183, 127-138.

Rasmussen, T. and Swedberg, M.D. (1998). Reinforcing effect of nicotinic compounds: intravenous self-administration in drug-naive mice. Pharmacology Biochemistry and Behavior, 60, 567-573.

Reavill, C. and Stolerman, I.P. (1990). Locomotor activity in rats after administration of nicotinic agonists intracerebrally. British Journal of Pharmacology, 99, 273-278.

Reid, M.S., Ho, I.B. and Berger, S.P. (1998). Behavioral and neurochemical components of nicotine sensitization following 15-day pretreatment: studies on contextual conditioning. Behavioral Pharmacology, 9, 137-148.

Risner, M.E. and Goldberg, S.R. (1983). A comparison of nicotine and cocaine selfadministration in the dog: fixed-ratio and progressive-ratio schedules of intravenous drug infusion. Journal of Pharmacology and Experimental Therapeutics, 224, 319-326.

Robinson, S.F., Marks, M.J. and Collins, A.C. (1996). Inbred mouse strains vary in oral self-selection of nicotine. Psychopharmacology, 124, 332-339.

Rosecrans, J.A. (1969). Effects of nicotine on exploratory behaviour of female rats. Pharmacologist, 11, 246.

Routtenberg, A. (1968). "Self-starvation: of rats living in activity wheels: adaptation effects. Journal of Comparative and Physiological Psychology, 66, 234-238.

Routtenberg, A. and Kuznesof, A.W. (1967). Self-starvation of rats living in activity wheels on a restricted feeding schedule. Journal of Comparative and Physiological Psychology, 64, 414-421.

Salamone, J.D., Cousins, M.S. and Snyder, B.J. (1997). Behavioral functions of nucleus accumbens dopamine: empirical and conceptual problems with the anhedonia hypothesis. Neuroscience and Biobehavioral Reviews, 21, 341-359.

Sannerud, C.A., Prada, J., Goldberg, D.M. and Goldberg, S.R. (1994). The effects of sertraline on nicotine self-administration and food-maintained responding in squirrel monkeys. European Journal of Pharmacology, 271, 461-469.

Santos, R.M. and Routtenberg, A. (1972). Attention of brain stimulations self-starvation: adaptation effects. Physiology and Behavior, 9, 831-837.

Schaefer, G.J. and Michael, R.P. (1986). Changes in response rates and reinforcement thresholds for intracranial self-stimulation during morphine withdrawal. Pharmacology Biochemistry and Behavior, 25, 1263-1269.

Schaefer, G.J. and Michael, R.P. (1992). Interactions between alcohol and nicotine on intracranial self-stimulation and locomotor activity in rats. Drug and Alcohol Dependence, 30, 37-47.

Schechter, M.D. and Rosecrans, J.A. (1972). Nicotine as a discriminative cue in rats: inability of related drugs to produce a nicotine-like effect. Psychopharmacologia, 27, 379-387.

Schilstrom, B., Svensson, H.M., Svensson, T.H. and Nomikos, G.G. (1998). Nicotine and food induced dopamine release in the nucleus accumbens of the rat: putative role of alpha 7 nicotinic receptors in the ventral tegmental area. Neuroscience, 85, 1005-1009.

Schlatter, J. and Battig, K. (1979). Differential effects of nicotine and amphetamine on locomotor activity and maze exploration in two rat lines. Psychopharmacology, 64, 155-161.

Schultz, W. (1997). Dopamine neurons and their role in reward mechanisms. Current Opinions in Neurobiology, 7, 191-197.

Schultz, W., Dayan, P.R. and Montague, P.R. (1997). A neural substrate of prediction and reward. Science, 275, 1593-1599.

Schwid, S.R., Hirvonen, M.D. and Keesey, R.E. (1992). Nicotine effects on body weight: a regulatory perspective. American Journal of Clinical Nutrition, 55, 878-884. 
Shaham, Y., Adamson, L.K., Grocki, S. and Corrigall, W.A. (1997). Reinstatement and spontaneous recovery of nicotine seeking in rats [published erratum appears in Psychopharmacology, (1997), 133, 106]. Psychopharmacology, 130, 396-403.

Shoaib, M., Schindler, C.W. and Goldberg, S.R. (1997). Nicotine self-administration in rats: strain and nicotine pre-exposure effects on acquisition. Psychopharmacology, 129, 35-43.

Shoaib, M. and Stolerman, I.P. (1996). Brain sites mediating the discriminative stimulus effects of nicotine in rats. Behavioral Brain Research, 78, 183-188.

Shoaib, M. and Stolerman, I.P. (1999). Plasma nicotine and cotinine levels following intravenous nicotine self-administration in rats. Psychopharmacology, 143, 318-321.

Shoaib, M., Stolerman, I.P. and Kumar, R. (1994). Nicotine-induced place preferences following prior nicotine exposure in rats. Psychopharmacology, 113, 445-452.

Shoaib, M., Swanner, L.S., Yasar, S. and Goldberg, S.R. (1999). Chronic caffeine exposure potentiates nicotine self-administration in rats. Psychopharmacology, 142, 327-333.

Singer, G., Simpson, F. and Lang, W.J. (1978). Schedule induced self-injection of nicotine with recovered body weight. Pharmacology Biochemistry and Behavior, 9, 387-389.

Slifer, B.L. and Balster, R.L. (1985). Intravenous self-administration of nicotine: with and without schedule-induction. Pharmacology Biochemistry and Behavior, 22, 61-69.

Smith, A. and Roberts, D.C. (1995). Oral self-administration of sweetened nicotine solutions by rats. Psychopharmacology, 120, 341-346.

Smith, L.A. and Lang, W.J. (1980). Changes occurring in self administration of nicotine by rats over a 28-day period. Pharmacology Biochemistry and Behavior, 13, 251-220.

Sorg, B.A. and Kalivas, P.W. (1991). Effects of cocaine and footshock stress on extracellular dopamine levels in the ventral straitum. Brain Research, 559, 29-36.

Spatz, C. and Jones, S.D. (1971). Starvation anorexia as an explanation of "self-starvation" of rats living in activity wheels. Journal of Comparative and Physiological Psychology, 77, 313-317.

Spealman, R.D. and Goldberg, S.R. (1982). Maintenance of schedule-controlled behavior by intravenous injections of nicotine in squirrel monkeys. Journal of Pharmacology and Experimental Therapeutics, 223, 402-408.

Spigelman, M.N., McLeod, W.S. and Rockman, G.E. (1991). Caloric vs. pharmacologic effects of ethanol consumption on activity anorexia in rats. Pharmacology Biochemistry and Behavior, 39, 85-90.

Stolerman, I.P., Fink, R. and Jarvik, M.E. (1973). Acute and chronic tolerance to nicotine measured by activity in rats. Psychopharmacologia, 30, 329-342.

Stolerman, I.P. and Jarvis, M.J. (1995). The scientific case that nicotine is addictive Psychopharmacology, 117, 2-10.

Stolerman, I.P., Naylor, C., Elmer, G.I. and Goldberg, S.R. (1999). Discrimination and self-administration of nicotine by inbred strains of mice. Psychopharmacology, 141, 297-306.

Sugimoto, Y., Yamada, J. and Noma, T. (1998). Effects of anxiolitics, diazepam and tandospirone, on immobilization stress-induced hyperglycemia in mice. Life Science, 63, 1221-1226.

Tessari, M., Valerio, E., Chiamulera, C. and Beardsley, P.M. (1995). Nicotine reinforcement in rats with histories of cocaine self-administration. Psychopharmacology, 121, 282-283.

Tobacco Advisory Group of The Royal College of Physicians (2000). Nicotine Addiction in Britain. Royal College of Physicians, London.

US Department of Health and Human Services (1988). Nicotine Addiction: A Report of the Surgeon General, DHHS Publication Number (CDC) 88-8406. US Department 
of health and Human Services, Office of the Assistant Secretary for Health, Rockville, Office on Smoking and Health, MD.

Valentine, J.D., Hokanson, J.S., Matta, S.G. and Sharp, B.M. (1997). Selfadministration in rats allowed unlimited access to nicotine. Psychopharmacology, 133, 300-304.

Van der Heyden, J.A., Zethof, T.J. and Olivier, B. (1997). Stress-induced hyperthermia in singly housed mice. Physiology and Behavior, 62, 463-470.

Vela, G., Martin, S., Garcia-Gil, L., Crespo, J.A., Ruiz-Gayo, M., Fernandez-Ruiz, J.J., Garcia-Lecumberri, C., Pelaprat, D., Fuentes, J.A., Ramos, J.A. and Ambrosio, E. (1998). Maternal exposure to delta ${ }^{9}$-tetrahydrocannabinol facilitates morphine self-administration behavior and changes regional binding to central mu opioid receptors in adult offspring female rats. Brain Research, 807, 101-109.

Wakasa, Y., Takada, K. and Yanagita, T. (1995). Reinforcing effect as a function of infusion speed in intravenous self-administration of nicotine in rhesus monkeys. Nihon Shinkei Seishin Yakurigaku Zasshi, 15, 53-59.

Watanabe, K., Hara, C. and Ogawa, N. (1992). Feeding conditions and estrous cycle of female rats under the activity-stress procedure from aspects of anorexia nervosa. Physiology and Behavior, 51, 832.

Watkins, S.S., Epping-Jordan, M.P., Koob, G.F. and Markou A. (1999). Blockade of nicotine self-administration with nicotinic antagonists in rats. Pharmacology Biochemistry and Behavior, 62, 743-751.

Weltzl, H., Alessandri, B., Oettinger, R. and Battig, K. (1988). The effects of long-term nicotine treatment on locomotion, exploration and memory in young and old rats. Psychopharmacology, 96, 317-323.

White, J.M. and Ganguzza, C.C. (1985). Effects of Nicotine on schedule-controlled behavior. Role of fixed-interval length and modification by mecamylamine and chlorpromazine. Neuropharmacology, 24, 75-82.

White, N.M. (1989). Reward or reinforcement: what's the difference? Neuroscience and Biobehavioral Reviews, 13, 181-186.

Williams, D.I. and Lowe, G. (1972). Light reinforcement in the rat: the effects of continuous and discontinuous periods of apparatus familiarization. Quarterly Journal of Experimental Psychology, 24, 98-101.

Wilson, M.C., Hitomi, M. and Schuster, C.R. (1971). Psychomotor stimulant self-administration as a function of dosage per injection in the rhesus monkey. Psychopharmacologia, 22, 271-281.

Wise, R.A. (1982). Neuroleptics and operant behavior: the anhedonia hypothesis. Behavioral Brain Science, 5, 39-87.

Wise, R.A. and Bozarth, M.A. (1987). A psychomotor stimulant theory of addiction. Psychological Reviews, 94, 469-492.

Wise, R.A., Leone, P., Rivest, R. and Leeb, K. (1995). Elevations of nucleus accumbens dopamine and DOPAC levels during intravenous heroin self-administration. Synapse, 21, 140-148.

Wise, R.A., Spindler, J., De Wit, H. and Gerberg, G.J. (1978). Neuroleptic-induced 'anhedonia' in rats: pimozide blocks reward quality of food. Science, 201, 262-264.

Woods, D.J. and Routtenberg, A. (1971). "Self-starvation" in activity wheels: developmental and chlorpromazine interactions. Journal of Comparative and Physiological Psychology, 76, 84-93.

Yanagita, T. (1977). Brief review on the use of self-administration techniques for predicting drug dependence potential. In: Thompson, T. and Unna, K.R. (Eds.), Predicting Dependence Liability of Stimulant and Depressant Drugs. Baltimore University Park Press, Baltimore.

Zarrindats, M.R. and Oveisi, M.R. (1997). Effects of monoamine receptor antagonists on nicotine-induced hypophagia in the rat. European Journal of Pharmacology, 321, 157-162. 